\title{
REDES FAMILIARES Y ESTRATEGIAS DE PODER EN LA MISERICÓRDIA DE MONÇÃO DURANTE EL SIGLO XVIII
}

\author{
Maria Marta LOBO DE ARAÚJO \\ Universidade do Minho
}

\begin{abstract}
RESUMEN: Nuestro trabajo estudia el acceso y el ejercicio de poder dentro de la Misericórdia de Monção a lo largo del siglo XVIII, destacando las estrategias familiares para ejercer y controlar dicho poder. Tierra pequeña y fronteriza, Monção presentaba pocas oportunidades para las familias más poderosas de la villa y de los alrededores. La Misericordia, al igual que el Ayuntamiento y el Ejército, se transformó para los poderosos en uno de los principales palcos de actuación, consintiendo el tráfico de influencias, la formación de redes de poder y la renovación de sus cuerpos gerentes.
\end{abstract}

PALABRAS CLAVE: Misericordia, caridad, redes familiares, estrategias de poder.

ABSTRACT: Our work studies the access and the exercise of power inside the Misericórdia of Monção throughout the XVIII century, enhancing the familiar strategies to exercise and controlling the power. Small town and frontier, Monção presented few opportunities to the most powerful families of the village and its surroundings. The Misericórdia, the Town all and the Army, became to the powerful people one of the main fields of action, becoming an influence path, in the formation of nets of power and in the weak renovation of its board managers.

KEYWORDS: Misericordia, charity, family nets, strategies of power.

Tierra fronteriza ${ }^{1}$, Monção (situado en el Alto Miño - Portugal) tiene parte de su historia marcada por su situación geográfica, hecho que se asocia a algunos momentos de la Historia portuguesa, concretamente en lo que se refiere a los conflictos bélicos.

A partir de 1498 se inició en Portugal, con la creación de la Misericordia de Lisboa, un movimiento de edificación de estas cofradías por todas las ciudades y

${ }^{1}$ Hemos decidido en algunos casos mantener algunas palabras en portugués como mesario, provedor..., dado que el funcionamiento de las Misericordias en España cuenta con una organización diferente. En estos casos se añade una nota a pie de página que aclara y explica el término, sobretodo en aquellos casos en los que es difícil encontrar uno equivalente en español. 
villas del reino, tanto en la metrópoli, como en su imperio. Esta costumbre de instalación de Misericordias debió llegar a Monção muy tempranamente, si bien desconocemos la fecha concreta.

Y es que datar la creación de la Misericordia de la villa no es tarea fácil; aunque algunos investigadores se la han atribuido al rey D. Manuel I, ni la documentación custodiada en esa institución ni la de los archivos centrales nos ofrecen pistas al respecto. El memoralista Francisco Xavier de Macedo, cuando envió el texto sobre la parroquia de Monção, en 1758, mencionó la existencia de una cofradía de Misericordia en la villa, fundada en el "tiempo del Señor rey Don Manuel"2. A pesar de que la fecha de fundación es difícil de concretar, se sabe, de todos modos, que en 1561, la Santa Casa de Monção estaba en pleno funcionamiento. Aquel año incorporaba por orden del rey D. Sebastião la leprosería de S. Gião. Esa donación por parte del monarca, le reportó a la institución importantes beneficios procedentes del destacado patrimonio con el que contaba la leprosería. En contrapartida, la Misericordia se encargó, a partir de entonces, de satisfacer las obligaciones a las que aquel establecimiento estaba vinculado ${ }^{3}$.

La aparición de las Misericordias en Portugal se integra dentro del contexto general de reformas en el mundo asistencial que se dio en toda Europa y que se constató igualmente en tierras lusitanas. De hecho, las cofradías de Misericordia fueron el punto culminante de ese proceso. Estas instituciones estaban especialmente dirigidas hacia la práctica de las catorce obras de misericordia y su creación bebió directamente del clima de renovación de la espiritualidad laica ${ }^{4}$.

Eran cofradías de seglares, de institución regia, estaban compuestas por "hombres de buena conciencia y fama, temerosos de Dios, modestos, caritativos y humildes, los cuales se requieren para servir a Dios y a sus pobres con la debida perfección",

2 Para esta materia véase CAPELA, José Viriato Eiras (2003). Memórias Paroquiais. Proyecto “A descrição do território português no siglo XVIII", in CAPELA, José Viriato Eiras (coord.), Monção nas Memórias Paroquiais de 1758, Braga, Casa Museu de Monção y Câmara Municipal de Monção, p. 405.

3 Arquivo da Santa Casa de Monção (de ahora en adelante ASCMM), Tombo dos bens e propriedades pertencentes à Santa Casa da Misericórdia de Monção 1788, fls. 40-42.

4 Léase SousA, Ivo Carneiro de (1999). Da descoberta da Misericórdia à fundação das Misericórdias (1498-1525), Porto, Granito, Editores e Livreiros Lda, pp. 181, 132-148.

${ }^{5}$ Consúltese Compromisso da Misericórdia de Lisboa, Lisboa, Pedro Gaesbeeck, 1619, p. 1. 
Constituían, por consiguiente, "universos masculinos" muy prestigiosos no sólo por las finalidades que perseguían, sino también por la calidad de sus miembros. Compuestas por hombres nobles y oficiales en igual proporción, las Misericordias operaban con numerus clausus, convirtiéndose en las cofradías más importantes a nivel local e integrando en ellas a las elites de la tierra.

El hecho de tratarse de las cofradías más prestigiosas, las convertía en un objeto muy solicitado por las clases medias y altas, no logrando formar parte de ellas todos los que lo pretendían. En primer lugar, como hemos señalado, debido al hecho de que operaban con límite de inscritos. En segundo, porque era necesario pagar una tasa de entrada ${ }^{6}$. Y en tercero, debido a que el compromiso establecía condiciones para la entrada de hermanos, obligando a los candidatos a someterse a un proceso de investigaciones. Los cofrades tenían que demostrar ser "limpios de sangre sin ninguna raza de Moro, o Judío no solamente en su persona, sino también en su esposa". Tenían igualmente que superar o al menos tener los 25 años. Asimismo, no podían ser asalariados de la Casa, y habían de saber leer y escribir, así como mostrar "buen entendimiento y saber". Los cofrades oficiales estaban también impedidos de "trabajar con las manos" ${ }^{\text {" }}$. Aquellos pocos que cumplían con todas esas condiciones deberían después superar los interrogatorios que se les hacían y lograr ser aceptados por la Mesa ${ }^{8}$. En la Misericordia de Monção los pretendientes se veían obligados a superar otro importante obstáculo, puesto que los familiares de hermanos tenían preferencia.

La entrada en la cofradía estaba reglada y no preveía privilegios para nadie, de todos modos poseer lazos de consanguinidad con los cofrades era un factor de mucho peso. Tal como se comprueba en la Misericordia de Baía, donde integrar la Misericordia local era una tradición de familia ${ }^{9}$, también en Monção muchos de los nuevos miembros tenían ascendentes familiares que militaban en la cofradía, constituyendo un fuerte argumento para ser aceptados.

${ }^{6}$ El pago de una cuota a la entrada no se comprueba en todas las Misericordias, aunque era práctica seguida en muchas y registrada también en Monção.

${ }^{7}$ Compromisso da Misericórdia de Lisboa..., pp. 3-4.

${ }^{8}$ La Mesa era el órgano de gobierno más importante de la institución y estaba compuesta por siete hermanos nobles y seis oficiales.

${ }^{9}$ Para la Misericórdia de Baía léase Russel-Wood, A. J. R., (1968). Fidalgos e Filantropos. A Santa Casa da Misericórdia da Bahia 1550-1755, Brasília, Editora Universidade de Brasília, p. 91. 
João Gonçalves Rebelo fue admitido, en 1700, en la Santa Casa como cofrade, "por ser hijo de hermano que la sirvió siempre bien"10. En una institución con estas características, el ingreso estaba facilitado cuando se poseían lazos de parentesco en su interior, sobre todo en los casos en los que los cofrades reconocían haber sido buenos servidores.

Cuando el familiar había ejercido los más elevados cargos de la institución, como era la "provedoría", las razones eran aún de mayor peso. En 1702, el licenciado Francisco Nogueira Falcão se postuló como hermano ${ }^{11}$. Después de haber analizado su petición y por "ser hijo de "provedor" que fue en esta casa todos unánimemente acordaron que le darían su asiento" ". El nuevo hermano era hijo del Reverendo Manuel Marinho Falcão, quien había sido "provedor" en años anteriores, motivo suficiente para que su admisión fuese votada favorablemente por unanimidad.

También era común que los hijos de los "provedores" entrasen en la institución durante la "provedoría" de los padres. Se trataba de un acto de fortalecimiento y de vitalidad de la cofradía que reforzaba el poder de quien la dirigía y subrayaba los lazos familiares en el cuerpo de los hermanos. Era una marca cargada de simbolismo que se dejaba durante el período en el que se gestionaba la institución. En 1753, durante la "provedoría" de Simão Pereira Velho de Moscoso, su hijo Marcos Pereira Velho de Moscoso se alistó como miembro ${ }^{13}$.

Todos los "provedores" que tenían hijos en edad de postularse aprovechaban su "proveduría" para hacerlo. No era extraño que muchos no reunieran todas las condiciones exigidas, sobre todo en lo que respecta a la edad. Sin embargo, atendiendo a su relación familiar con el "provedor", el ingreso era consentido. Era pues el poder del padre, cabeza de la Misericordia, el que le abría las puertas de la cofradía más prestigiosa del entorno al hijo, reforzando, a su vez, su propio poder

${ }^{10}$ Ascmm, Libro que serve dos Assentos dos hermanos desta Santa Caza da Miziricordia desta villa de Monção 1670, nº 42, fl. 44.

${ }^{11}$ El provedor era un hermano noble que presidía la Mesa y que ocupaba el lugar más importante de la institución. El compromiso de la Misericórdia de Lisboa de 1618 refiere que el provedor "será siempre un hombre hidalgo, de autoridad, prudencia, virtud, reputación y edad que los otros hermanos lo puedan reconocer por cabeza”. Léase Compromisso da Misericórdia de Lisboa..., p. 14. El provedor era siempre elegido entre los hombres más reputados e importantes de la tierra.

12 Ascmm, Livro que serve dos Assentos..., no 42, fl. 46.

${ }^{13}$ Ascmm, Livro que serve dos Assentos..., $\mathrm{n}^{\circ}$ 42, fl. 84v. 
personal. Al mismo tiempo, y tratándose de una cofradía con límite de hermanos, con estas medidas se excluía a eventuales candidatos que hubieran mostrado interés por ingresar en la institución. La Misericordia protegía a los que ya eran sus miembros y simultáneamente creaba redes de complicidad y poder dentro de sus filas.

En la Misericordia de Fundão, los familiares de hermanos tenían igualmente preferencia sobre los restantes candidatos, porque se consideraba la participación de éstos en las tareas y obligaciones de la cofradía, no sólo "con sus personas [sino también] con sus haciendas" ${ }^{14}$.

Era frecuente que los "mesarios" contribuyesen con limosnas a la cofradía y que los "provedores" efectuasen obras a sus expensas o diesen limosnas durante su mandato ${ }^{15}$.

Además de esta distinción que muestra el poder de algunas familias dentro de la institución, hay evidencias también a otros niveles.

No hay ninguna duda de que los cofrades no gozaban todos del mismo trato, observándose prácticas de favores y presiones procedentes de los más poderosos. Como hemos señalado, en la Misericordia de Monção, se exigía el pago de una tasa de entrada a los nuevos miembros. Pero este pago no era efectuado por todos. Félix Pereira de Castro, hijo del hermano Félix Pereira de Castro "no dio la entrada por ser hijo y nieto de Provedores", cuando se alistó en la cofradía, en abril de $1753^{16}$. Esta cláusula no existe en el compromiso, pero posiblemente pueda tratarse de una resolución de la Mesa acordada entre los "mesarios" para distinguir a algunos familiares ${ }^{17}$. De todos modos, muestra el trato privilegiado que disfrutaban algunos

${ }^{14}$ Consúltese CORReIA, Manuel Antunes (1971). Subsídios para a História da Santa Casa da Misericórdia do Fundão (sécs. XVI, XVII e XVIII), Coimbra, Faculdade de Letras, p. 147, dis. de licenciatura policopiada.

${ }^{15}$ En la Misericórdia de Caminha, los mesarios contribuían anualmente con una limosna, la cual se destinaba a efectuar una compra o realizar alguna obra que fuese necesaria. Arquivo da Santa Casa da Misericórdia de Caminha, Livro de receyta e despeza 1616-1626, fls. 4 e 60. En Monção, varios provedores señalaron su provedoría con limosnas ofrecidas por ellos mismos.

${ }^{16}$ Ascmm, Livro que serve dos Assentos..., n 42 , fl. 85.

${ }^{17}$ Esta Misericórdia perdió parte de su archivo cuando la guerra de la Restauración, impidiéndonos conocer las resoluciones de la Mesa durante los siglos XVI y XVII. 
individuos dentro de la institución y sobre el resto de cofrades. Se trataba de miembros de las elites locales que habían accedido a la "provedoría"18.

La familia Pereira de Castro, aunque residía en la villa, contaba con ramificaciones familiares en las parroquias del Municipio. Se trataba de uno de los linajes más poderosos del entorno y estuvo asociado al ejercicio del poder en la Misericordia a lo largo de todo el siglo XVIII. Su poder alcanzaba tales niveles que tenía aseguradas estas distinciones. Así, el propio Félix Pereira de Castro, padre, en ausencia del escribano, fue quien registró a su hijo en la institución.

La historia se repitió con otro hijo, António Tomás Pereira de Castro, el cual también fue inscrito el mismo año y no pagó derecho alguno por integrarse en la cofradía. Una vez más, y sin ninguna explicación, fue el padre quien inscribió al hijo.

El hecho es realmente significativo, puesto que todas las tareas de registro eran de la incumbencia del escribano y a los restantes "mesarios" se les impedía estatutariamente efectuar cualquier registro. La osadía consentida en el registro de los Pereira de Castro habla por sí misma de la fuerza de estos hombres en el interior de la Misericordia y de la facilidad con la que en ella se movían, accediendo incluso al importante control de su notaría.

La práctica de la exención a los hijos de los "provedores" parecía estar absolutamente instaurada. El Dr. José João Teixeira también estuvo exento de la cuantía de 800 réis (cantidad de la tasa de entrada a mediados del siglo XVIII), por ser hijo del Dr. Pedro Esteves Teixeira, hermano que había ejercido la "provedoría", además de otros cargos ${ }^{19}$. El Dr. Pedro Esteves Teixeira era abogado, vivía en la villa de Monção y fue un hombre muy poderoso dentro de la Misericordia. Su prestigio se materializa en los cargos para los que fue electo en la Santa Casa. Se alistó en la cofradía en 1710 y desde 1712 hasta 1750, año en el que murió, estuvo casi siempre asociado al poder en la institución, ocupando los puestos de "provedor", escribano y mesario. Como era jurista de profesión, sirvió muchas veces a la Misericordia en los tribunales, tratando casos que la arrastraron hasta las redes de la justicia. Era, por tanto, un elemento con crédito, dispuesto, que mostraba capacidades y dedicación a la cofradía, útil, por consiguiente, a la

${ }^{18}$ Sobre la ascensión de las elites al poder véase el reciente trabajo de MONTEIRO Nuno Gonçalo (2003). Elites e poder entre o Antigo Regime e o Liberalismo, Lisboa, Instituto de Ciências Sociais, pp. 66-80.

${ }^{19}$ Ascmm, Livro que serve dos Assentos..., no 42, fl. 89. 
institución. Por eso la Misericordia, en reconocimiento de los servicios prestados, distinguió a su hijo y a él lo trató siempre con deferencia.

Las Misericordias integraban a las elites de la tierra, residentes normalmente en la sede del concejo, teniendo una especial implantación en la parroquia de la villa ${ }^{20}$. En Monção, esta situación se repetía y la mayoría de los cofrades residía en la cabecera del concejo. Se registra, de todos modos, la inclusión de algunos señores nobles que habitaban en sus quintas y palacios en las parroquias vecinas y que se desplazaban a la villa para gobernar la Misericordia y/o para integrar las regidurías del Ayuntamiento. Muchos de estos hombres servían al Ejército, ocupando los lugares de mayor relieve en la defensa de la villa. Eran, por tanto, la posesión de la tierra $^{21}$ y la ocupación de cargos militares las bases del poder y prestigio de estos hombres.

El desempeño de las tareas de la cofradía, sobre todo para los "mesarios", no era compatible con residencias alejadas de la sede del concejo ${ }^{22}$. Este hecho explica el reclutamiento de hermanos principalmente en la villa y extra-muros, forzando su permanencia por algunas temporadas en las casas que poseían en Monção, para facilitar el cumplimiento de las obligaciones confraternales.

Es el estudio de los cargos directivos el testimonio más fidedigno de la presencia e influencia de determinadas redes familiares cómodamente instaladas en la Misericordia. Estas instituciones se gestionaban por una Mesa, elegida anualmente los días 2 y 3 de julio. Este órgano contaba con el auxilio, para algunas decisiones, de una Junta, del mismo modo elegida anualmente, cada 10 de agosto. Este segundo órgano no tenía mucho poder en la Misericordia de Monção y raramente se alude a ella en su documentación. Desconocemos su constitución y su funcionamiento.

20 Para esta problemática véase CAPELA, José Viriato Eiras (2003). Os "ilustres" de Monção. Paradigmas e referências da sociedade aristocrática monçanense ao tempo das Memórias Paroquiais, in CAPEla, José Viriato Eiras (org.), Monção nas Memórias Paroquiais de Monção de 1758..., p. 183.

${ }^{21}$ Sobre la base del poder de las oligarquías extremeñas españolas en el Antiguo Régimen léase Pereira Iglesias, José Luis (1993). Las oligarquías extremenãs en el Antiguo Régimen, en Les élites locales et l'état dans l'Espagne Moderne XVIe-XVIIIe siècles, Paris, CNRS, pp. 79-96.

${ }^{22}$ Las Mesas se reunían todos los domingos y miércoles, pero los hermanos estaban obligados además a participar en muchas otras atribuciones: peticiones, entierros, visitar enfermos, ayudar a presos, distribuir limosnas, efectuar cobros, etc. 
El día 2 de julio, los hermanos debían comparecer personalmente en la sede de la cofradía para escoger a sus cuerpos gerentes. Se trataba de un momento de gran trascendencia para la hermandad, que debía movilizar a todos los cofrades. A pesar de ello, en algunas Misericordias el acto era muy poco concurrido, apareciendo tan sólo los interesados en perpetuar su poder dentro de la institución ${ }^{23}$.

La elección de la Mesa era precedida por una misa y se extendía durante dos días. El acto se desarrollaba dentro de la iglesia y obedecía a un ritual descrito en el compromiso. Después de que el capellán hubiese leído el capítulo referente al acto electoral, los hermanos prometían "votar sólo en las personas, que según Dios y su conciencia le pareciesen más acomodadas, y dignas de ser Electores de los oficiales que han de servir al año siguiente" ${ }^{24}$ y escogían a 10 hermanos. Los estatutos les impedían elegir a los hermanos que hubiesen servido en la Mesa durante los dos años anteriores. Una vez acabado el escrutinio, los votos permanecían cerrados y el proceso sólo se concluía al día siguiente.

La selección de estos cofrades era fundamental pues en esta elección era donde las familias poderosas se jugaban buena parte de sus posibilidades para acceder a los mandatos anuales. Dominar la selección de los electores era ganar, ya que eran estos hermanos quienes escogían los órganos directivos de la Santa Casa. Se trataba, en consecuencia, de una elección indirecta.

Al día siguiente, una vez celebrada la misa, se abrían las puertas y se llamaba a los escogidos para dar continuidad al proceso electoral. De dos en dos (un hermano noble y otro oficial) procedían a la elección de los "mesarios". Los electores no podían votar a hermanos que hubiesen servido en los tres años precedentes, ni a sí mismos. Concluido el acto, se anunciaba la constitución de la nueva Mesa.

Los actos electorales se transformaban en momentos de gran significado e importancia para estas instituciones. Los intereses eran muchos, dado que las Misericordias eran ricas y prestigiosas: desempeñaban una importante labor asistencial, administraban importantes legados, prestaban dinero con intereses, facilitaban el tráfico de influencias y de poder y eran permeables a las redes de intereses. Acceder a los puestos de poder conllevaba innegables ventajas y para obtenerlas se cuidaba de la elección de los electores.

${ }^{23}$ El reciente trabajo sobre la Misericórdia de Ponte da Barca muestra que eran muy pocos los hermanos que aparecían en los actos electorales. Léase PEREIRA, Maria das Dores Sousa (2003). Entre ricos e pobres: a actuação da Santa Casa da Misericórdia de Ponte da Barca (1630-1800), Braga, Universidade do Minho, pp. 43-45, dis. de mestrado policopiada.

${ }^{24}$ Léase Compromisso da Misericórdia de Lisboa..., p. 9. 
Muchas Misericordias registran fraudes electorales, actos ilícitos, escenas poco edificantes, pero muy significativas en cuanto al tráfico de influencias que se hacía sentir dentro de ellas y a los intereses familiares que se registraban ${ }^{25}$. Instalado el conflicto y detectada la incapacidad de resolución en el interior de la institución, era en la Corona donde se buscaba la solución, a través normalmente del Corregidor de la Comarca que asistía a la repetición del acto electoral. Eran situaciones excepcionales, que desagradaban a los cofrades ya que estaban poco habituados a la presencia de los representantes de la Corona en su sede ${ }^{26}$.

Dentro de los miembros de la Misericordia de Monção se registraban también un número importante de soldados. Algunos pertenecían a las elites locales, mientras que otros se encontraban destacados en aquella plaza cumpliendo el servicio militar. Por ser tierra fronteriza, Monção estaba protegida por un respetable contingente castrense. La presencia del Ejército se hacía sentir en la villa, pero también en la Santa Casa, donde se alistaban como hermanos y se hacían con el poder, ocupando cargos en la Mesa.

En la segunda mitad del siglo XVIII, se conoce también la ascensión de los letrados, a semejanza de lo que se verifica en cofradías congéneres ${ }^{27}$.

La mayoría de los militares que perteneció a la institución era de condición noble, status que alcanzaron debido, precisamente, a los servicios prestados en el Ejército $^{28}$.

25 Sobre los fraudes electorales en las Misericórdias léase SÁ, Isabel dos Guimarães (1997). Quando o rico se faz pobre: Misericórdias, caridade e poder no império português 1500-1800, Lisboa, Comissão Nacional para os Descobrimentos Portugueses, pp. 216-220.

${ }^{26}$ Aunque las Misericordias estuviesen obligadas a prestar cuentas a la Corona, en la práctica eran autónomas y no estaban habituadas a ser "vigiladas" por ningún órgano. Por eso, reaccionaban mal cuando se veían obligadas a abrir sus puertas a los representantes del poder central, aunque fuese para regularizar una situación que ellas no podían resolver.

27 Para la ascensión de los letrados al poder, bien sea en las Misericordias, bien en los Ayuntamientos véase CAPELA, José Viriato Eiras (1991). O Município de Braga de 1750 a 1834. O governo e a administração económica e financeira, Braga, s. n., pp. 37-38; CAPELA, José Viriato Eiras (2002). Vila Nova de Cerveira. Elites, poder e governo municipal (1753-1834), Braga, Universidade do Minho, pp. 57-65.

28 A pesar de que muchos elementos del Ejército no eran nobles, ascendían a esa condición por las funciones que ejercían y eso les facilitaba el ingreso en la Misericordia en esa situación. Véase para esta temática CAPELA, José Viriato Eiras (2003). Os "ilustres" de Monção. Paradigmas e referências da sociedade aristocrática monçanense ao tempo das Memórias Paroquiais, in José Viriato Eiras Capela, Monção nas Memórias Paroquiais de 1758..., p. 184. 
Pasemos a continuación a analizar, a través de dos familias de Monção, el papel de esas redes de poder. Escogemos a dos familias nobles, aunque los mismos intereses se evidenciaban en el comportamiento de los oficiales ${ }^{29}$. La familia Pereira de Castro se mantuvo en los cargos de poder de la institución a lo largo de todo el siglo XVIII ${ }^{30}$. Poseemos, también, algunas informaciones que evidencian que su poder ya venía de los siglos anteriores. Los Pereira de Castro situaban a sus hombres en los puestos más importantes de la Misericordia, detentando, de esta forma, el poder.

\begin{tabular}{ccc} 
Gaspar Pereira de Castro & Gaspar Pereira de Castro & Félix Pereira de Castro \\
\hline (padre, entró en 1674) & (hijo, entró en 1711) & (nieto, entró en 1729) \\
Mesario 1711-12 & Mesario 1718-19 & Mesario 1729-30 \\
Mesario 1713-14 & Mesario 1724-25 & Mesario 1732-33 \\
Mesario 1727-28 & Mesario 1726-27 & Escribano 1733-34 \\
Mesario 1733-34 & Mesario 1731-32 & Mesario 1735-36 \\
Mesario 1735-36 & Mesario 1737-37 & Escribano 1738-39 \\
& Mesario 1740-41 & Mesario 1739-40 \\
& Mesario 1742-43 & Mesario 1740-41 \\
& Mesario 1744-45 & Provedor 1743-44 \\
& Mesario 1746-47 & Escribano 1745-46 \\
& Mesario 1748-49 & Provedor 1746-47 \\
& Mesario 1750-51 & Mesario 1748-49 \\
& Mesario 1752-53 & Escribano 1750-51 \\
& Mesario 1754-55 & Mesario 1752-53 \\
& Mesario 1756-57 & \\
& Mesario 1759-60 & \\
& Mesario 1761-62 & \\
& Escribano 1762-63 & \\
& Mesario 1764-65 &
\end{tabular}

Alexandre Pereira de Castro

Bento António Pereira de Castro (biznieto, entró en 1746)

Mesario 1747-48 (trinieto, entró en 1773)

Mesario 1749-50 Mesario 1774-75

Mesario 1751-52

Mesario 1776-76

Mesario 1780-81

\footnotetext{
${ }^{29}$ Véase a propósito Pereira, Maria das Dores de Sousa (2003). Entre ricos e pobres: a actuação da Santa Casa da Misericórdia de Ponte da Barca (1630-1800)..., pp. 66-67.

${ }^{30}$ Aunque no tengamos series de registros electorales para los siglos anteriores, sabemos que los Pereira de Castro se instalaron en los órganos directivos de la Santa Casa desde siglos XVI y XVII.
} 
Mesario 1753-54

Escribano $1754-55$

Mesario 1756-57

Escribano $1757-58$

Mesario 1759-60

Provedor 1761-62
Mesario 1781-82

Mesario 1883-84

Mesario 1786-88

Mesario 1789-90

Mesario 1791-92

Mesario 1793-94

Mesario 1795-96

Mesario 1796-97

Mesario 1799-1800

Hemos seleccionado tan sólo algunos integrantes de la familia Pereira de Castro, sin embargo a lo largo de cerca de 130 años (1670-1800), esta familia llegó a poner a 34 hombres en los cargos de gestión de la Santa Casa. Como no disponemos de fuentes que nos ayuden a estudiar el proceso electoral completo, es decir, a saber quiénes fueron los electores, desconocemos como se posicionaron los Pereira de Castro en este capítulo. La documentación existente tampoco nos facilita conocer a los miembros de la Junta ${ }^{31}$, sin embargo, sí estamos seguros de que los hombres de esta familia no dejarían de integrarla. Así, estarían en todos los órganos de gestión de la Santa Casa de forma permanente.

Pasemos pues a un análisis más detallado sobre la estrategia de esta familia para mantenerse en el poder de la cofradía. Como puede observarse, fue sobretodo a través del puesto de "mesario" como sus integrantes sirvieron a la Misericordia. En raras ocasiones ocuparon los puestos de escribanos y "provedores". Éstos, que se adecuaban más a un lugar de status y prestigio que el cargo de "provedor", fueron cedidos a otras familias, igualmente poderosas. Pero ¿por qué no habrán luchado estos hombres por la "provedoría" más veces? Ignoramos la respuesta. De lo que estamos seguros es de que su participación en la Mesa les facilitaba un papel relevante en la toma de decisiones y un importante poder en la institución. Si por un lado, el cargo de "provedor" era el de mayor prestigio, por otro, no tenía derecho a veto. De esta forma, parece que los Pereira de Castro consideraron más importante el número, tratando de elegir a varios hombres para la misma Mesa. Por otro lado, eran hombres de la villa, con fuerte implantación en el entorno y

31 La Junta o Definitorio era un órgano compuesto por un número variable de hermanos de acuerdo con el numerus clausus de la cofradía. En Ponte de Lima, integraba 16 elementos (ocho nobles y ocho oficiales), mientras que en Lisboa estaba compuesto por 10 hermanos nobles y 10 oficiales. Era electa anualmente cada 10 de agosto y trataba de algunos asuntos importantes de la institución: expulsión de hermanos, aceptación de legados, entierros, entre otros. 
conocedores de toda la realidad social y de la política local. Tal vez, por eso, con este perfil le interesasen más a la gestión cotidiana de la Misericordia.

Es importante destacar también que otros muchos elementos de esta familia actuaron simultáneamente en la Mesa. Varias veces Gaspar Pereira Sousa, hijo, ocupó lugar en la Mesa con su hermano, Gonçalo Pereira de Castro. También Alexandre Pereira de Castro fue "mesario" varias veces, compartiendo puesto con el suyo Félix Pereira de Castro. Añádase también que otros familiares estuvieron igualmente al mismo tiempo en los cargos directivos. Veamos, por ejemplo, la constitución de la mesa en 1781: integraba, entre otros personajes, a João Ventura Pereira de Castro, Antonio Pereira de Araújo, Félix José Pereira de Castro, Bento Antonio Pereira de Castro y Francisco Manuel Castro Araújo, todos ellos parientes $^{32}$. Es decir, más del $70 \%$ de los elementos nobles de la Mesa eran familiares próximos. Hemos tomado ese año al azar, pero podríamos haber escogido cualquier otro y los resultados no serían muy diferentes. La presencia aplastante de los Pereira de Castro en los puestos de decisión de la cofradía ilustra la voluntad de permanecer y los intereses que los mantenían instalados en el poder.

Además de los familiares de la villa, este linaje tenía ramificaciones en las parroquias rurales del concejo, donde residían en sus casas de campo, cruzándose también con otras familias poderosas, tanto del ámbito más inmediato, como incluso de todo el Alto Miño.

A través del matrimonio entroncaron con otras casas nobles de los alrededores, haciéndose igualmente presentes en la Misericordia: los Castro Araújo y los Araújo Pereira, parientes suyos, también ocuparon cargos en la Santa Casa. Esto significa que además de los descendientes directos, muchos otros parientes accedían a los puestos de poder de la Misericordia ${ }^{33}$.

32 Esta realidad era común en muchas Misericordias. Para Ponte de Lima léase ARAúJo, Maria Marta Lobo de (2000). Dar aos pobres e emprestar a Deus: as Misericórdias de Vila Viçosa e Ponte de Lima (siglos XVI-XVIII), Barcelos, Santa Casa da Misericórdia de Vila Viçosa; Santa Casa da Misericórdia de Ponte de Lima, pp. 408-411. Para Guimarães léase CosTA, Américo Fernando da Silva (1999) A Santa Casa da Misericórdia de Guimarães 1650-1800. (Caridade e assistência no meio vimaranense dos siglos XVII e XVIII), Guimarães, Santa Casa da Misericórdia de Guimarães, pp. 62-63. Para Setúbal consúltese Abreu, Laurinda Faria dos Santos (1990). A Santa Casa da Misericórdia de Setúbal de 1500 a 1755: aspectos de sociabilidade e poder, Setúbal, Santa Casa da Misericórdia de Setúbal, p. 137.

33 Para las estrategias familiares de casamientos véase MATEO RIPOLL, Verónica Mateo (1994). Oligarquía y poder en el Siglo XVIII, Alicante, Instituto de Cultura "Juan Gil-Albert", Diputación de Alicante, pp. 143-146. Para las alianzas matrimoniales en Vizcaya léase MARTINEZ RUEDA, Fernando 
La presencia permanente de esta familia en los cargos de gestión de la Santa Casa significa que fue elegida para constituir una de sus plataformas de actuación, cerrándose a la integración de otros elementos, así como a la renovación de sus cuerpos gerentes. Esto significa además que no se cumplía lo estipulado en su normativa, que determinaba intervalos a cumplir para acceder de nuevo al desempeño de cargos. Eran las redes de parentesco y la instalación de los intereses familiares las que actuaban dentro de la cofradía.

Analicemos ahora el poder de los Pita Palhares en la Misericordia. Esta familia utilizó una estrategia diferente de la de los Pereira de Castro, pero con el mismo éxito. Prefirieron mantenerse menos tiempo en los cargos de gestión, sin embargo su prioridad fue ocupar el lugar más importante: la "provedoría". También el segundo lugar, el de escribano, se les entregó en varias ocasiones.

Muchos de los Pita Palhares estuvieron en la gestión de la Misericordia con anterioridad a 1710, pero sobretodo sería a partir de la figura de Sebastião João Pereira Pita Palhares Brandão cuando la familia cobró fuerza en la hermandad.

\begin{tabular}{cc} 
João Pereira Pita Palhares Brandão & Sebastião José Pita Palhares Antas Marinho \\
\hline Escribano 1711-12 & Escribano 1741-42 \\
Mesario 1717-18 & Mesario 1743-44 \\
Escribano 1719-20 & Mesario 1745-46 \\
Mesario 1722-23 & Escribano 1747-48 \\
Escribano 1724-25 & Provedor 1750-51 \\
Mesario 1727-28 & Mesario 1753-54 \\
Mesario 1730-31 & Mesario 1756-57 \\
Mesario 1731-32 & Mesario 1760-61 \\
& Escribano 1761-62 \\
& Provedor 1762-63 \\
& Provedor 1767-68 \\
& Mesario 1775-76 \\
& Provedor 1776-77 \\
& Mesario Pita Palhares Antas Marinho \\
Mesario 1799-90 \\
Mesario 1793-94 \\
Provedor 1794-95 \\
Escribano 1799-1800
\end{tabular}

(1994). Los poderes locales en Vizcaya. Del Antiguo Régimen a la Revolución Liberal 1700-1853, Bilbao, Universidad del País Vasco, pp. 211-218. 
También José de Melo Pita Palhares empezó a desempeñar cargos en la Misericordia, en 1797. En este año fue elegido como "provedor" y en 1799 llegó a escribano, precisamente los dos cargos más importantes de la institución. Como parece, tanto António Pita Palhares Antas Marinho como José de Melo Pita Palhares estaban aún iniciando su carrera en la institución, cuando los dejamos de observar. De este modo, queda patente que esta familia prefirió el desempeño de los cargos más prestigiosos dentro de la cofradía: el de "provedor" y el de escribano. Esta familia estuvo igualmente presente a través de los lazos que estableció con los Meneses. Así, también algunos Palhares y Meneses fueron elegidos para representar a la cofradía a través de la ocupación de lugares en la Mesa.

Los señores del pazo de Barbeita (parroquia del concejo de Monção) siguieron la misma senda que los Pita Palhares. Gonçalo Afonso Pereira Melo Soto Maior, alcalde de la villa de Caminha e hidalgo de la Casa de Su Majestad, sirvió a la cofradía tan sólo durante dos años, ocupando la "provedoría" en 1729-30 y en 1730-40. Su hijo, Gonçalo Afonso Pereira Melo Soto Maior, igualmente hidalgo de la Casa de Su Majestad, le siguió los pasos y fue "provedor" en 1777-78 y en 178182. Estos hombres fueron preparados tan sólo para la "provedoría". No ocuparon otros cargos en la institución. Ser "mesario" los obligaba a tareas que probablemente no deseaban cumplir. Prefirieron, por tanto, reservarse para este puesto y ocupar el cargo más prestigioso.

Otras familias estuvieron también en la gestión de la Santa Casa de Monção, a lo largo de todo el siglo XVIII: los Magalhães de Meneses, señores unidos por lazos de parentesco con los Magalhães de Meneses de Ponte da Barca y los Abreu de Lima, parientes de los Abreu de Lima de Ponte de Lima, quienes se mantuvieron en el poder de la Misericordia de esta villa a lo largo de los siglos XVII y XVIII ${ }^{34}$. La presencia aplastante de esta familia en todos los cargos de gestión de la Misericordia de Ponte de Lima de forma continua, nos conduce a concluir su toma de poder en esta institución.

Sin embargo, ¿cuál era la razón del interés de estas familias en la Misericordia? Estamos seguros de que la práctica de la caridad asociada a la voluntad de salvar su alma sería un motivo muy fuerte para integrarse en estas asociaciones. Después, el interés planeado de la ocupación de cargos estaría fuertemente relacionado con los servicios, bienes y riqueza que caracterizaban a estas instituciones. La integración

${ }^{34}$ Sobre la ocupación de cargos de esta familia en la Misericórdia de Ponte de Lima véase ARaúJo, Maria Marta Lobo de (2000). Dar aos pobres e emprestar a Deus..., pp. 408-410. 
de estas cofradías obedecía a motivos espirituales, pero también a sociales y políticos $^{35}$. La caridad era un acto muy valorado y arrastraba ganancias celestiales y terrenas $^{36}$. Originaba también manifestaciones de gratitud por parte de los pobres que reforzaban el poder de las elites. Por eso, eran elegidos para purificar sus riquezas a favor de los más desfavorecidos ${ }^{37}$. Al ponerse al servicio de las instituciones de caridad para servir a los pobres, los poderosos, se servían también a sí mismos, en la medida en que su gestión les otorgaba la oportunidad de acceder a más poder y a bienes terrenos.

La participación de los dos casos seleccionados para la Misericordia de Monção nos permite comprobar que estas familias se mantuvieron a lo largo del siglo XVIII en los cargos más importantes de la cofradía, monopolizándolos. Esta situación contradecía el compromiso que obligaba la rotatividad de los mismos, sin embargo los intereses locales eran mayores y permitieron el incumplimiento de la norma. La transposición de la ley ocurrió también durante el siglo XVII, pero se volvió más evidente a lo largo del siglo siguiente. La rotatividad fue cada vez menor y se comprobó entre los elementos de las mismas familias. La entrada de otros elementos fue rara y se comprueba que no accedían con facilidad a los lugares de gestión. Se registra, entonces, una concentración acentuada de los cargos en un número pequeño de hermanos, que monopolizaban la cofradía, disponiendo de un capital simbólico muy grande dentro y fuera de la institución.

La selección de estos hombres para los puestos de jefatura demuestra la existencia de redes de poder, de complicidades e incluso de intereses instalados. El ejercicio del poder era tan sólo consentido a algunos, señaladamente a los que perpetuaban su presencia en la institución. Era un grupo restringido, que actuaba con intención de garantizar su presencia o la de uno de los familiares en uno de los pilares más importantes del poder local: la Misericordia. La actuación de estos hombres se extendía también al Ayuntamiento, donde ocupaban las regidurías. Se

35 Mesgravis, Laima (1976). A Santa Casa da Misericórdia de S. Paulo (1599?-1884), São Paulo, Conselho Estadual de Cultura, p. 45; SÁ, Isabel dos Guimarães (2001). As Misericórdias Portuguesas de D. Manuel I a Pombal, Lisboa, Livros Horizonte, pp. 61-78.

36 Léase CAVAllo, Sandra (1995). Charity and power in early modern Italy: benefactors and their motives in Turim: 1541-1789, Cambridge, University Press, pp. 8296; CHARTIER, Roger (1974). Les élites et les gueux: quelques représentations: XVIeXVIIe siècles. Revue d' Histoire Moderne et Contemporaine. 21, pp. 376-388.

${ }^{37}$ Sobre las prácticas asistenciales de las elites de Évora véase PARDAL, Rute (2002). A influência da estrutura sócio-política das elites eborenses nas práticas assistenciais: 1580-1640. Revista de Demografia Histórica, XX, pp. 99-110. 
repartían pues entre la Misericordia y el Ayuntamiento, ocupando, de manera rotativa o acumulando, los lugares más importantes del poder en términos locales ${ }^{38}$.

La acentuación de estas familias en la gestión de la Misericordia estuvo igualmente relacionada con el hecho de que Monção era una villa pequeña, sin grandes alternativas para sustituir la presencia de estos hombres y además con el hecho de que la cofradía evidenciaba dificultades para atraer a nuevos miembros. Se añade también que las opciones para otras ocupaciones no eran abundantes para las elites locales. Además del Ayuntamiento, la Misericordia y el Ejército, pocas más opciones tendrían. Así, si por un lado los miembros instalados en la institución demostraban interés en continuar, cuidando de su elección y no "permitiendo" la renovación de los cuadros, como determinaba el compromiso, por otro, la alternativa era débil, ya que era dentro de las mismas familias donde se conocían los nuevos ingresos.

Se trataba de familias influyentes que mantenían el poder concentrado y estructurado en fuertes lazos de parentesco. Estos individuos constituyeron y mantuvieron clientelas dentro de la Misericordia, que los sustentaron en el poder y alejaban a hipotéticos interesados en acceder a los cargos directivos de la institución ${ }^{39}$. Eran familias dominantes, interesadas en conservar su poder y que actuaban para perpetuarlo.

El poder de la Misericordia de Monção se encontró a lo largo del siglo XVIII en manos de un grupo restringido de hombres ricos, de la misma familia o parientes entre sí, que gozaban de un estatuto privilegiado en términos locales y que ejercían de forma asfixiante el poder en la cofradía. Contando con el consentimiento y apoyo de los restantes miembros de la institución, estos hermanos se mantuvieron a lo largo de todo el periodo en estudio al frente de los destinos de la Santa Casa, engrandeciendo su poder y el de su familia.

${ }^{38}$ Véase CAPELA, José Viriato Eiras (1999). Fidalgos, nobres e letrados no governo municipal bracarense. A administração económica e financeira da Câmara no Antigo Regime, Braga, Universidade do Minho, pp. 40-58. Para España Martinez RuedA, Fernando (1996). Poder Local oligarquías en el País Vasco: las estrategias del grupo dominante en la comunidad tradicional, en Imízcoz BeunZA, José Maria (dir.), Elites, poder y red social. Las elites del País Vasco y Navarra en la Edade Moderna, Gipuzkoa, Universidad del País Vasco, pp. 119-125.

39 Sobre la instalación de redes clientelares consúltese XAVIER, Ângela Barreto Xavier; Hespanha, António Manuel (1993). "As redes clientelares", in Mattoso, José (dir.), História de Portugal, vol. IV, Lisboa, Círculo de Leitores, p. 389. 